\title{
Pengaruh Informasi Akuntansi terhadap Harga Saham Serta Dampaknya terhadap PBV pada Sub Sektor Farmasi yang Terdaftar di BEI
}

\author{
Khairul Azwar \\ Sekolah Tinggi Ilmu Ekonomi Sultan Agung \\ khairulazwar@stiesultanagung.ac.id

\section{Elly Susanti} \\ Sekolah Tinggi Ilmu Ekonomi Sultan Agung \\ ellysusanti@stiesultanagung.ac.id

\section{Widia Astuty} \\ Universitas Muhammadiyah Sumatera Utara \\ widiaastuty@umsu.ac.id
}

\begin{abstract}
Abstrak This research was conducted to determine the effect of accounting information on stock prices and their impact on PBV. Data analysis techniques with path analysis. This research is in the pharmaceutical sub-sector. The results of the F test study, obtained independent variables affect the dependent variable. In t-test accounting information does not have a significant effect on stock prices, while the ROE variable has an effect on stock prices. Furthermore, for stock prices, there is no impact between the influence of accounting information on $P B V$.
\end{abstract}

Kata Kunci current ratio, DER, ROE, stock prices, PBV

\section{PENDAHULUAN}

Pasar modal merupakan wadah dalam memperjualbelikan instrumen keuangan. Saham merupakan salah satu istrumen tersebut.Dengan memiliki kinerja yang bagus akan meningkatkan harga saham, hal ini menarik investor dalam melakukan investasi kepada perusahaan (Meythi et al., 2013). Dengan demikian hal ini membuat perubahaan pada harga saham. Indek harga saham memberikan informasi bahwa emiten formasi anjlok dikarenakan penurunan nilai rupiah sehingga investor ragu-ragu dalam berinvestasi pada emiten farmasi tersebut. Dengan demikian akan berimbas pada dilepasnya saham-saham emiten farmasi. (Rupiah terpuruk, Harga Saham Emiten Farmasi Anjlok, n.d.)

Nilai perusahan dilihat berdasarkan harga saham, yang memberikan gambaran kesempatan dalam berinvestasi(Denziana \& Monica, 2016). Kemampuan perusahaan dalam menciptakan nilai pesaranya terlihat dari nilai perusahaan (Silitonga et al., 2019), maka dengan mengetahui tingkatan nilai perusahaan akan memberikan informasi mengenai peluang berinvestasi bagi investor. Infromasi tersebut meningkatkan permintaan saham maka harga sahammeningkatkan yang berimbas 
kepada peningkatan nilai perusahaan. Dengan tingkat nilai perusahaan yang semakin tinggi maka kesejahterahaan pemilik akan terjamin (Silitonga et al., 2019). Pengembangan PBV membuat investor percaya akan prospek masa depan perusahaan (Mulyana \& Saputra, 2017). Nilai PBV dapat digunakan dalam membandingkan saham perusahaan dengan saham lainnya. Selainnya harga saham hal yang mempengaruhinya ialah informasi akuntansi suatu perusahaan. Pada Tabel 1 berikut ini disajikan informasi akuntansi, harga saham, nilai perusahaan Sub Sektor Farmasi pada periode penelitian.

Tabel 1: Data Informasi Akuntansi, Harga Saham, PBV

\begin{tabular}{|l|l|l|l|l|l|l|}
\hline Tahun & $\begin{array}{c}\text { CR } \\
\text { (Kali) }\end{array}$ & $\begin{array}{c}\text { Size } \\
\text { (Kali) }\end{array}$ & $\begin{array}{c}\text { DER } \\
\text { (Kali) }\end{array}$ & $\begin{array}{c}\text { ROE } \\
\text { (Kali) }\end{array}$ & $\begin{array}{c}\text { HargaSaham } \\
(\text { Rp) }\end{array}$ & $\begin{array}{c}\text { PBV } \\
\text { (Kali) }\end{array}$ \\
\hline 2015 & 2,5523 & 28,3025 & 0,4122 & 0,1524 & 1.811 & 3,1474 \\
\hline 2016 & 3,7253 & 28,4270 & 0,4390 & 0,1523 & $1.827,429$ & 3,5373 \\
\hline 2017 & 3,6649 & 28,5264 & 0,6026 & 0,1518 & $2.482,571$ & 3,6434 \\
\hline 2018 & 2,8300 & 28,7000 & 0,6900 & 0,4400 & 2.557 & 3,4200 \\
\hline
\end{tabular}

Sumber : Data Diolah (2020)

Berdasarkan tabel di atas, diperoleh CR dan ROE pada tahun 2017 terjadipenurunan dengan nilai PBV mengalami peningkatan. Sizedan DERmeningkatkan pada tahun 2018, dimana nilai PBV sedang menurun, sedangkan nilai TOE juag mengalami peningkatan. Selanjutnya nilai harga saham pada tahun 2018 jugamengalami kenaikan mengalami peningkatan. Beberapa hasil penelitian yang dilakukan oleh (Welly, 2019), (Denziana \& Monica, 2016) serta (Novari \& Lestari, 2016) dengan hasil bahwa dengan meningkatkan profitabilitas dan ukuran perusahaan maka nilai perusahaan ikut meningkat, sedangkan peningkatan leverage akan menurunkan nilai perusahaan profitabilitas. Berbeda dengan penelitian menurut (Denziana \& Monica, 2016) dan (Pangaribuan et al., 2019)bahwa dengan meningkatkan nilai DER akan meningkatkan nilai perusahaan.

Berdasarkan gap research penelitian terdahulu tersebut penulis tertarik melakukan peneltiian tentang "Pengaruh Informasi Akuntansi Terhadap Harga Saham Serta Dampaknya Terhadap PBV Pada Sub Sektor Farmasi Yang Terdaftar Di Bursa Efek Indonesia”. Tujuan penelitian untuk mengetahui kontribusi informasi akuntansi terhadap harga saham dan dampaknya terhadap PBV.

\section{LANDASAN TEORI}

\subsection{Signalling Theory}

Laporan keuangan bagi investor digunakan untuk mengungkap informasi yang diangggap penting dalam melakukan investasi oleh investor tersebut (Novalia \& Nindito, 2016). Jika investor mempercayai sinyal yang diberikan oleh perusahaan maka hal ini akan memberikan nilai positif kepada perusahaan.

\subsection{Pecking Order Theory}

Preferensi menentukan struktur modal perusahaan yang optimal. Perusahaan lebih ditekankan dalam penggunaan dana menggunakan modal sendiri pendaan dari luar 
sebagai alternatif terakhir dalam melakukan pinjaman (Dewi \& Wirama, 2017). Tetapi hal ini bertentangan dengan respon investor. Jika perusahaan melakukan pinjaman kepada pihak eksternal maka hal ini direspon baik oleh investor namun sebaliknya jika perusahaan menerbitkan sekuritas ekuitas maka hal ini direspon kurang baik oleh investor. Investor beranggapan bahwa dengan meningkatkan jumlah pinjaman untuk kegiatan operasional perusahaan maka hal ini memberikan kepercayaan kepada manajemen perusahaan mampu menghasilkan keuntungan, sehingga perusahaan tidak perlu khawatir dalam pembayaran pinjaman dan bunga pinjaman tersebut.

\subsection{CURRENT RATIO}

Informasi current ratio digunakan investor untuk mengetahui sejauh mana kemampuan aset perusahaan memenuhi kewajiban lancarnya (Inrawan et al., 2020). Dengan mengukur Current ratiomaka akan diketahui tingkat likuid perusahaan dalam memenuhi kewajiban lancar (Jufrizen \& Sagala, 2019).Rasio CR diukur dengan menggunakan rumus:

$$
\text { Current Ratio }=\frac{\text { Asset Lancar }}{\text { Liabilitas Jangka Pendek }}
$$

\subsection{SIZE}

Size merupakan klasifikasi ukuranbesar/kecil suatu organisasi(Panggabean et al., 2019). Perusahaan yang ukuran besar akan mendapatkan kepercayaan lebih dari investor, karena perusahaan tersebut lebih dikenal oleh masyarakat. Perusahaan dengan ukuran besar akan mempunyai aset yang cukup besar, hal inimenjadi magnetdalam berinvestasi(Novari \& Lestari, 2016). Rumus size adalah LN (Total Aset).

\subsection{DEBT TO EQUITY RATIO (DER)}

DER dalam memiliki kesenjangan dimana akan meningkatkan biaya yang dapat mengurangi keuntungan, dan disisi lain dengan pertumbuhan DER menunjukkan tingkat kepercayaan dari investor yang dapat meningkatkan nilai perusahaan (Osazuwa \& CheAhmad, 2016). Kebijksanaan manajemen dalam mengelola efek negatif dari DER akan membuat modal yang dimiliki perusahaan semakin besar dan memberikan peluang dalam meningkatkan aktifitas perusahaan dalam meningkatkan keuntungan (Mufidah \& Azizah, 2018). Untuk mengukur tingkat DER, sebagai berikut:

$$
\text { Debt equity ratio }=\frac{\text { Total Hu tang }}{\text { Total Ekuitas }}
$$

\subsection{RETURN ON EQUITY (ROE)}

Laba digunakan sebagai ukuran kinerja perusahaan, keuntungan memberikan gambaran kinerja (Mulyana \& Saputra, 2017). ROEdigunakan mengukur kapabilitas perusahaan dalam menggunakan modola untuk memperoleh keuntngan (Ikhwal, 2016).Dengan tingkat ROE yang tinggi maka pengelolaan modal yang dimiliki untuk meningkatkan aktiiftas perusahaan dalam meningkatkan keuntungan. Rumus dari ROE, sebagai berikut:

$$
\text { Return On Equity }=\frac{\text { Laba Setelah Pajak }}{\text { Total Ekuitas }}
$$




\subsection{Harga Saham}

Saham merupakan alternatif yang menarik bagi investor, karena harga saham mempengaruhi keuntungan perusahaan (Zaki et al., 2017). Harga saham akan meningkat jika permintaannya semakin tinggi. Harga saham penutupan akhir periode merupakan harga yang digunakan untuk mengukur nilai saham (Sihombing et al., 2018). Dengan tingginya harga sahamhal ini menggambarkan tingginya kepercayaan investor dalam melakukan investasi. Dengan tingginya hal tersebut maka akan meningkatkan nilai perusahaan (Dwisona \& Haryanto, 2015). Harga saham menggunakan harga pada penutupan akhir periode.

\subsection{Price To Book Value (PBV)}

Persepsi investor tentang keuntungan dan arus kas perusahaan dikaitkan dengan harga saham (Silitonga et al., 2019). Rasio PBV digunakan investor dalam melaukan investasi dengan membandingkan harga saham dengan nilai buku (Utomo et al., 2016). Perusahaan yang memiliki rasio PBV diatas 1 maka perusahaan ini memiliki kinerja yang baik.

Price ToBook Value $=\frac{\text { Harga Saham }}{\text { Nilai Buku }}$

\section{METODOLOGI PENELITIAN}

Data kualitiatif terdiri dari CR, Size, DER, ROE, Harga Saham dan PBV. Data sekunder dalam penelitian ini diperloleh situs resmi BEI dengan menggunakan metode dokumentasi. Teknik analisis data, Uji Asumsi Klasik, Koefisien Determinasi, Uji Hipotesis, Path Analysis, dan Sobel Test.

\section{HASIL PENELITIAN}

\subsection{Uji Normalitas}

Tabel 2: Uji Normalitas

\begin{tabular}{|ll|r|}
\hline & & \multicolumn{1}{|c|}{ Unstandardized Residual } \\
\hline Normal Parameters ${ }^{\mathrm{a}, \mathrm{b}}$ & Mean & 28 \\
& Std. Deviation &, 0000000 \\
Most Extreme Differences & Absolute &, 64707590 \\
& Positive &, 109 \\
& Negative &, 109 \\
Kolmogorov-Smirnov Z & &,- 053 \\
Asymp. Sig. (2-tailed) & &, 578 \\
\hline
\end{tabular}

Sumber : Data Diolah (2020)

Berdasarkan Tabel 4.1, nilaiunstandarized residual> sigifikan 0,05, artinya seluruh variabel terdistribusi normal. 


\subsection{Uji Multikoliniearitas}

Tabel 3: Uji Multikoliniearitas

\begin{tabular}{|ll|r|r|l|}
\hline \multirow{2}{*}{ Model } & & \multicolumn{2}{|c|}{ Collinearity Statistics } & \multirow{2}{*}{ Keterangan } \\
\cline { 3 - 4 } & & Tolerance & VIF & \\
\hline 1 & (Constant) & & & \\
& LN_CR &, 486 & 2,057 & Tidak terjadi Multikolinearitas \\
& LN_SIZE &, 859 & 1,164 & Tidak terjadi Multikolinearitas \\
& LN_DER &, 470 & 2,126 & Tidak terjadi Multikolinearitas \\
& LN_ROE &, 890 & 1,124 & Tidak terjadi Multikolinearitas \\
\hline
\end{tabular}

Sumber : Data Diolah (2020)

Berdasarkan tabel 4.2, diketahui nilai TOL $>0,01$, artinya tidak terjadi multikolinearitas.

\subsection{Uji Heteroskedastisitas}

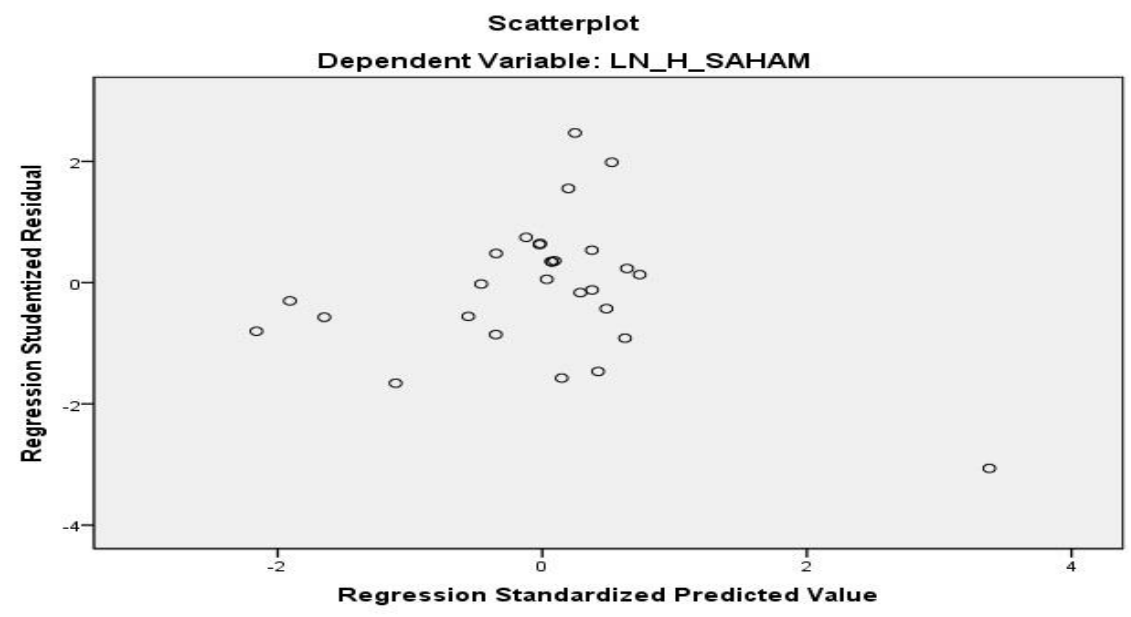

Gambar 1: Uji Heteroskedastisitas

Sumber : Data Diolah (2020)

Gambar 1, di atas terlihat titik-titik menyebar, yang artinya tidak terjadi Heteroskedastisitas.

\subsection{Uji Autokorelasi}

Tabel 4: Uji Autokorelasi Model Summary

\begin{tabular}{|c|c|c|c|c|c|c|c|c|c|c|}
\hline \multirow[b]{2}{*}{ Model } & \multirow[b]{2}{*}{$\mathrm{R}$} & \multirow[b]{2}{*}{$\begin{array}{c}\mathrm{R} \\
\text { Square }\end{array}$} & \multirow[b]{2}{*}{$\begin{array}{l}\text { Adjusted R } \\
\text { Square }\end{array}$} & \multirow{2}{*}{$\begin{array}{l}\text { Std. Error } \\
\text { of the } \\
\text { Estimate }\end{array}$} & \multicolumn{5}{|c|}{ Change Statistics } & \multirow[b]{2}{*}{$\begin{array}{l}\text { Durbin- } \\
\text { Watson }\end{array}$} \\
\hline & & & & & $\begin{array}{l}\text { R Square } \\
\text { Change }\end{array}$ & $\begin{array}{c}\mathrm{F} \\
\text { Change }\end{array}$ & df1 & df 2 & $\begin{array}{c}\text { Sig. F } \\
\text { Change }\end{array}$ & \\
\hline &, $815^{a}$ & ,665 & ,606 & ,70109 & ,665 & 11,402 & 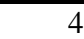 & 23 & ,000 & 2,35 \\
\hline
\end{tabular}

a. Predictors: (Constant), LN_ROE, LN_CR, LN_SIZE, LN_DER

b. Dependent Variable: LN_H_SAHAM

Sumber : Data Diolah (2020)

Berdasarkan tabel 4.3 Durbin-Watson untuk data sebanyak 28 dan variabel bebas $\mathrm{k}=4$, maka akan diperoleh nilai $\mathrm{dL}=1,1044$, nilai $4-\mathrm{dL}=2,8956$, nilai $\mathrm{dU}=1,7473$ dan nilai 4-dU = 2,2527. Maka nilai uji DW pada tabel 4.3 di atas berada 4 -dU $<\mathrm{d}<4$-dL 
atau dapat dijelaskan bahwa 2,2527 $<2,356<2,8956$, maka uji autokorelasi tanpa kesimpulan.

\subsection{Uji Hipotesis}

\subsubsection{Analisis Regresi Persamaan Sub Struktur 1}

Tabel 5: Regresi Persamaan Sub Struktur 1

\begin{tabular}{|ll|r|r|r|}
\hline \multirow{2}{*}{ Model } & \multicolumn{2}{|c|}{ Unstandardized Coefficients } & $\begin{array}{c}\text { Standardized } \\
\text { Coefficients }\end{array}$ \\
\cline { 3 - 5 } & & \multicolumn{1}{|c|}{ B } & Std. Error & \multicolumn{2}{|c|}{ Beta } \\
\hline 1 & (Constant) & $-10,089$ & 9,586 & \\
& LN_CR &,- 083 &, 289 &,- 050 \\
& LN_SIZE & 5,842 & 2,832 &, 269 \\
& LN_DER &, 353 &, 238 &, 260 \\
& LN_ROE &, 988 &, 191 &, 664 \\
\hline
\end{tabular}

Sumber : Hasil Pengolahan SPSS (2020)

Berdasarkan tabel 4.4 maka dapat dituliskan regresi berganda dari persamaan sub struktur 1 adalah LN_H_SAHAM= -10,089 - 0,083LN_CR + 5,842 LN_Size + 0,353LN_DER + 0,988LN_ROE

\subsubsection{Koefisien Determinasi $\left(\mathbf{R}^{2}\right)$}

Tabel 6: Koefisien Determinasi

\begin{tabular}{|c|c|c|c|c|}
\hline Model & $\mathrm{R}$ & R Square & Adjusted R Square & $\begin{array}{l}\text { Std. Error of the } \\
\text { Estimate }\end{array}$ \\
\hline 1 &, $815^{\mathrm{a}}$ & ,665 & ,606 & ,70109 \\
\hline
\end{tabular}

Sumber : Hasil Pengolahan SPSS (2020)

Adjusted $R$ Square sebesar 0,665 atau 66,5\% Harga Saham dipengaruhi oleh Infromasi Akuntansi sedangkan 33,5\% dipengaruhi oleh variabel lain.

\subsubsection{Uji F}

Tabel 7: Uji F

\begin{tabular}{|ll|r|r|r|r|r|}
\hline Model & & Sum of Squares & df & Mean Square & F & Sig. \\
\hline 1 & Regression & 22,417 & 4 & 5,604 & 11,402 &, $000^{\mathrm{a}}$ \\
& Residual & 11,305 & 23 &, 492 & & \\
& Total & 33,722 & 27 & & & \\
& & & & & \\
\hline
\end{tabular}

a. Predictors: (Constant), LN_ROE, LN_CR, LN_SIZE, LN_DER

b. Dependent Variable: LN_H_SAHAM

Sumber : Data Diolah (2020) signifikan.

Hasil Uji F, dengan nilai sig $0,000<\operatorname{sig} 0,05$ artinya seluruh variabel berpengaruh

\subsubsection{Uji t}

Tabel 8: Uji t 


\begin{tabular}{|ll|r|r|r|}
\hline \multirow{2}{*}{ Model } & \multicolumn{2}{|c|}{$\begin{array}{c}\text { Standardized } \\
\text { Coefficients }\end{array}$} & \multicolumn{1}{c|}{} \\
\cline { 3 - 3 } & \multicolumn{2}{|c|}{ Beta } & \multicolumn{1}{c|}{ Sig. } \\
\hline 1 & & & $-1,052$ &, 304 \\
& (Constant) &,- 050 &,- 286 &, 777 \\
& LN_CR &, 269 & 2,063 &, 051 \\
& LN_SIZE &, 260 & 1,479 &, 153 \\
& LN_DER &, 664 & 5,188 &, 000 \\
& LN_ROE & &
\end{tabular}

Sumber : Hasil Pengolahan SPSS (2020)

Pada tabel di atas diperoleh bahwa CR, size, dan DER tidak berpengaruh signifikan, dan ROE berpengaruh signifikan terhadap harga saham.

\subsubsection{Analisis Regresi Persamaan Sub Struktur 2}

Tabel 9: Regresi Persamaan Sub Struktur 2

\begin{tabular}{|ll|r|r|}
\hline \multirow{2}{*}{ Model } & \multicolumn{2}{|c|}{ Unstandardized Coefficients } \\
\cline { 3 - 4 } & B & \multicolumn{1}{|c|}{ Std. Error } \\
\hline (Constant) & $-14,998$ & 6,344 \\
& LN_CR &,- 034 &, 187 \\
LN_SIZE & 4,544 & 1,993 \\
& LN_DER &,- 071 &, 161 \\
& LN_ROE &, 410 &, 181 \\
& LN_H_SAHAM &, 213 &, 135 \\
\hline
\end{tabular}

Sumber : Pengolahan Data (2020)

Berdasarkan table 4.8 maka dapat dituliskan regresi berganda dari persamaan sub struktur 2 adalah LN_PBV = -14,998 - 0,034LN_CR + 4,544 LN_Size - 0,071LN_DER $+0,410 \mathrm{LN} \_$ROE $+0,213 \mathrm{LN} \_\mathrm{H} \_S A H A M$

\subsubsection{Koefisien Determinasi $\left(\mathbf{R}^{2}\right)$}

Tabel 10: Koefisien Determinasi

\begin{tabular}{|l|r|r|r|}
\hline Model & \multicolumn{1}{|c|}{ R } & R Square & Adjusted R Square \\
\hline 1 &, $844^{\mathrm{a}}$ &, 712 &, 647 \\
\hline
\end{tabular}

Sumber: Data Diolah (2020)

Nilai $R^{2}$ sebesar 0,712 yang mengindikasikan bahwa 71,2\% artinyaCR, Size, DER, ROE dan nilai perusahaan sedangkan $28,8 \%$ dipengaruhi oleh variabel lain. Error of Term pada model persamaan analisis jalur atau $\varepsilon 2$ senilai 0,536656 .

\subsubsection{Uji F}

Tabel 11: Uji F

ANOVA $^{b}$

\begin{tabular}{|ll|r|r|r|r|r|}
\hline Model & Sum of Squares & df & Mean Square & F & Sig. \\
\hline 1 & Regression & 11,191 & 5 & 2,238 & 10,899 &, $000^{\mathrm{a}}$ \\
& Residual & 4,518 & 22 &, 205 & & \\
& Total & 15,710 & 27 & & & \\
& & & & & \\
\end{tabular}

a. Predictors: (Constant), LN_H_SAHAM, LN_DER, LN_SIZE, LN_CR, LN_ROE

b. Dependent Variable: LN_PBV 
Sumber : Pengolahan Data (2020)

Hasil Uji F, nilai sig0,000> 0,05 artinya seluruh variabel berpengaruh signifikan terhadap PBV.

\subsubsection{Uji t}

Tabel 12: Uji t

\begin{tabular}{|ll|r|r|r|}
\hline \multirow{2}{*}{ Model } & \multicolumn{2}{|c|}{$\begin{array}{c}\text { Standardized } \\
\text { Coefficients }\end{array}$} & \multirow{2}{*}{ Sig. } \\
\cline { 3 - 3 } & Beta & \multicolumn{1}{|c|}{$\mathrm{t}$} &, 027 \\
& (Constant) & & $-2,364$ &, 855 \\
& LN_CR &,- 030 &,- 184 &, 033 \\
& LN_SIZE &, 306 & 2,281 &, 666 \\
& LN_DER &,- 076 &,- 438 &, 034 \\
& LN_ROE &, 403 & 2,259 &, 128 \\
& LN_H_SAHAM &, 312 & 1,580 & \\
& & &
\end{tabular}

Sumber : Hasil Pengolahan SPSS (2020)

Dari tabel di atas diperolehCR, DER dan harga saham tidak berpengaruh signifikan sedangkan size, dan ROE berpengaruh signifikan terhadap PBV.

\subsection{Analisis Jalur (Path Analysis)}

Berdasarkan gambar 2 maka diperoleh persamaan CR berdampak PBV senilai0,034, senilai -0,017679 (- 0,083 x 0,213). Jumlah dampak $C R$ terhadap $P B V$ senilai $0,034+(-0,017679)=-0,051679$, maka dapat disimpulkan bahwa harga saham memiliki dampak antara CR dengan PBV. Size berdampak langsung terhadap PBV senilai 4,544 dan berdampak tidak langsung terhadap PBV senilai 1,244348 (5,842 x 0,213). Jumlah dampak size terhadap PBV sebesar 4,544 + 1,244348 = 5,788348. Artinya harga saham tidak memiliki dampak antara size dengan PBV. DER berdampak langsung PBV sebesar $-0,071$ dan $0,075189(0,353 \times 0,213)$ untuk dampak tidak langsung. Total dampak DER terhadap PBV sebesar $-0,071+0,075189=0,004189$, artinya harga saham memiliki dampak antara DER dengan PBV. ROE berdampak PBV sebesar 0,410 dan 0,210444 $(0,988 \times 0,213)$ untuk dampak tidak langsung. Jumlah dampak ROE terhadap PBV sebesar 0,410 +0,210444 =0,620444. Maka harga saham tidak memiliki dampak antara ROE dengan PBV.

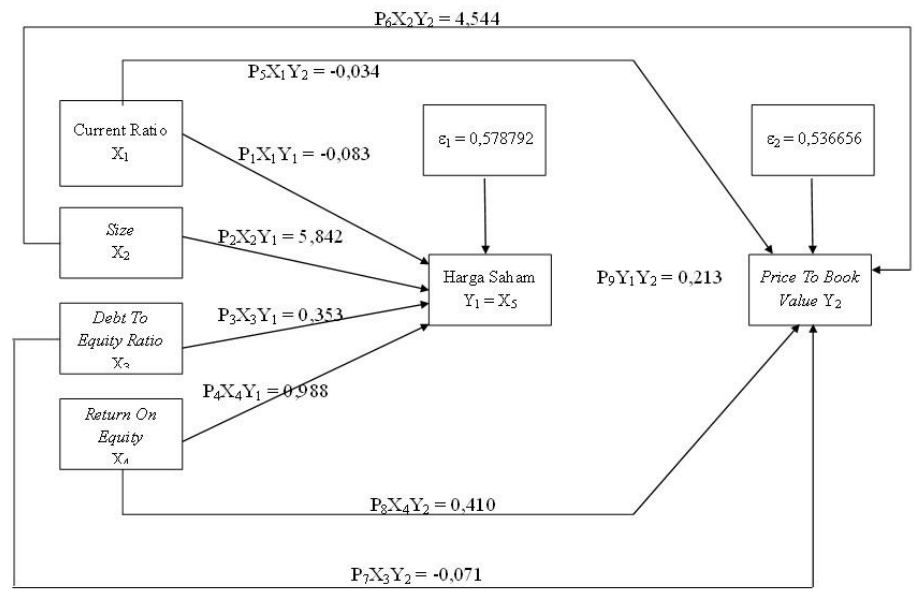




\subsection{Sobel Test}

Gambar 2: Analisis Jalur, Sumber : Data diolah (2020)

Pada tabel di bawah perhitungan sobel test tidak sejalan dengan hasil pengujian sebelumnya yang menunjukkan harga saham tidak memberikan dampak antara pada CR, size, DER, , dan ROE. Berdasarkan gambar dengan menggunakan sobel test nilai $\mathrm{p}$ value untuk setiap variabel indenpenden $>0,005$, artinya sehingga dapat disimpulkan harga saham tidak memberikan dampak antara informasi akuntansi dengan PBV. Hasil sobel test pada Tabel 13, sebagai berikut:

Tabel 13: Sobel Test

\begin{tabular}{|c|c|c|c|c|c|}
\hline $\begin{array}{c}\text { Variabel } \\
\text { Independen }\end{array}$ & $\begin{array}{c}\text { Variabel } \\
\text { Intervening }\end{array}$ & $\begin{array}{c}\text { Variabel } \\
\text { Dependen }\end{array}$ & $\begin{array}{c}\text { Koefisien } \\
\text { Jalur }\end{array}$ & $\begin{array}{l}p \text {-Value } \\
>0,05\end{array}$ & Keterangan \\
\hline Current Ratio & & & $-0,034$ & & $\begin{array}{c}\text { Tidak } \\
\text { Signifikan }\end{array}$ \\
\hline Size & & & 4,544 & & $\begin{array}{c}\text { Tidak } \\
\text { Signifikan }\end{array}$ \\
\hline $\begin{array}{c}\text { Debt to Equity } \\
\text { Ratio }\end{array}$ & & & $-0,071$ & & $\begin{array}{c}\text { Tidak } \\
\text { Signifikan }\end{array}$ \\
\hline $\begin{array}{l}\text { Return on } \\
\text { Equity }\end{array}$ & & & 0,410 & & $\begin{array}{c}\text { Tidak } \\
\text { Signifikan }\end{array}$ \\
\hline Current Ratio & Harga Saham & $\begin{array}{c}\text { Price To Book } \\
\text { Value }\end{array}$ & $-0,051679$ & $\begin{array}{c}0,778> \\
0,005\end{array}$ & $\begin{array}{c}\text { Tidak } \\
\text { variabel } \\
\text { Intervening }\end{array}$ \\
\hline Size & & & 5,788348 & $\begin{array}{c}0,210> \\
0,005\end{array}$ & $\begin{array}{c}\text { Tidak } \\
\text { variabel } \\
\text { Intervening }\end{array}$ \\
\hline $\begin{array}{l}\text { Debt to Equity } \\
\text { Ratio }\end{array}$ & & & 0,004189 & $\begin{array}{c}0,2798> \\
0,005\end{array}$ & $\begin{array}{c}\text { Tidak } \\
\text { variabel } \\
\text { Intervening }\end{array}$ \\
\hline $\begin{array}{l}\text { Return on } \\
\text { Equity }\end{array}$ & & & 0,620444 & $\begin{array}{c}0,131> \\
0,005\end{array}$ & $\begin{array}{c}\text { Tidak } \\
\text { variabel } \\
\text { Intervening }\end{array}$ \\
\hline
\end{tabular}

Sumber : Data Diolah (2020)

\section{KESIMPULAN}

Berdasarkan pembahasan yang telah dilakukan, maka diperoleh kesimpulan:

1. $\mathrm{CR}$, size dan DER ratio tidak berpengaruh, dimana ROE berpengaruh terhadap harga saham.

2. CR, DER dan harga saham tidak berpengaruh, dan size dan ROE berpengaruh terhadap PBV.

3. Path analysis dan sobel test menunjukkan hasil bahwa harga saham tidak mampu memberikan dampak antara variabel infromasi akuntansi terhadap PBV.

4. Harga saham dipengaruhi sebesar $66,5 \%$ oleh informasi akuntansi.

5. PBV dapat dijelaskan informasi akuntansi dan harga saham sebesar $71,2 \%$ 


\section{DAFTAR PUSTAKA}

Denziana, A., \& Monica, W. (2016). Analisis Ukuran Perusahaan dan Profitabilitas Terhadap Nilai Perusahaan (Studi Empiris Pada Perusahaan yang tergolong LQ45 di BEI Periode 2011 - 2014). IOSR Journal of Economics and Finance, 7(2), 241254. https://doi.org/https://doi.org/10.3929/ethz-b-000238666

Dewi, P. S. M. Y., \& Wirama, D. G. (2017). PECKING ORDER THEORY: PENGARUH PROFITABILITAS DAN PERTUMBUHAN PERUSAHAAN PADA KEPUTUSAN PENDANAAN PERUSAHAAN. E-Jurnal Akuntansi Universitas Udayana, 18(3), 2423-2450.

Dwisona, S. W., \& Haryanto, A. M. (2015). Analisis Pengaruh Faktor Fundamental Terhadap Harga Saham Dengan ROA Sebagai Variabel Intervening pada Perusahaan LQ 45Periode 2010-2013. Diponegoro Journal Of Management, 4(3), $1-13$.

Ikhwal, N. (2016). Analisis Roa Dan Roe Terhadap Profitabilitas Bank Di Bursa Efek Indonesia. Al-Masraf : Jurnal Lembaga Keuangan Dan Perbankan, 1(2), 211-226.

Inrawan, A., Jubi, Silitonga, H. P., \& Sudirman, A. (2020). PENGARUH LIKUIDITAS DAN SOLVABILITAS TERHADAP RENTABILITAS MODAL SENDIRI PADA PKPRI DI KABUPATEN SIMALUNGUN. 5(1), 1-15.

Jufrizen, \& Sagala, D. A. P. H. (2019). Effect of Current Ratio, Debt to Equity Ratio, Net Profit Margin, and Total Asset TurnOver on Earning Per Share. International Conference on Global Education VII "Humanising Technology For IR 4.0, ” 15071521.

Meythi, Kwang, E. T., \& Linda, R. (2013). Pengaruh Likuiditas dan Profitabilitas Terhadap Harga Saham Perusahaan Manufaktur yang Terdaftar di Bursa Efek Indonesia. Journal of Chemical Information and Modeling, 53(9), 1689-1699. https://doi.org/10.1017/CBO9781107415324.004

Mufidah, H. L., \& Azizah, D. F. (2018). Pengaruh Rasio Aktivitas dan Rasio Leverage Terhadap Profitabilitas (studi Pada Perusahaan Sub Sektor Food and Beverages yang terdaftar di BEI Periode 2012 - 2016). Jurnal Administrasi Bisnis (JAB), $59(1), 1-7$.

Mulyana, A., \& Saputra, M. (2017). The Influence of Liquidity, Profitability and Leverage on Profit Management and Its Impact on Company Value in Manufacturing Company Listed on Indonesia Stock Exchange Year 2011-2015. International Journal of Managerial Studies and Research, 6(1), 8-14. https://doi.org/10.20431/2349-0349.0601002

Novalia, F., \& Nindito, M. (2016). Pengaruh Konservatisme Akuntansi dan Economic Value Added Terhadap Penilaian Ekuitas Perusahaana. Jurnal Ilmiah Wahana Akuntansi, 11(2), 1-13.

Novari, P. M., \& Lestari, P. V. (2016). PROFITABILITAS TERHADAP NILAI PERUSAHAAN PADA SEKTOR Fakultas Ekonomi dan Bisnis Universitas Udayana ( Unud ), Bali , Indonesia PENDAHULUAN Mempertahankan kontinuitas perusahaan adalah elemen penting yang harus dipertahankan oleh perusahaan , terutama men. E-Jurnal Manajemen Unud, 5(9), 5671-5694. 
Osazuwa, N. P., \& Che-Ahmad, A. (2016). The moderating effect of profitability and leverage on the relationship between eco-efficiency and firm value in publicly traded Malaysian firms. Social Responsibility Journal, 12(2), 295-306. https://doi.org/10.1108/SRJ-03-2015-0034

Pangaribuan, L. N., Susanti, E., Putri, J. A., \& Sembiring, L. D. (2019). FINANCIAL: Jurnal Akuntansi KEBIJAKAN HUTANG DAN KEBIJAKAN DIVIDEN TERHADAP NILAI PERUSAHAAN PADA SUB SEKTOR ROKOK YANG Sektor Rokok yang terdaftar di Bursa Efek Payout Ratio ( DPR) dan Tobin' s $Q$ pada Perusahaan Sub Sektor Rokok yang terdaftar di Burs. 5, 80-90.

Panggabean, V. D. Y., Inrawan, A., Silitonga, H. P., \& Sembiring, L. D. (2019). DAMPAK STRUKTUR ASET DAN UKURAN PERUSAHAAN TERHADAP STRUKTUR MODAL. 4328.

Rupiah terpuruk, Harga Saham Emiten Farmasi Anjlok. (n.d.).

Sihombing, M. J. T., Nasution, S., \& Nainggolan, S. (2018). Faktor - Faktor Yang Mempengaruhi Return Saham Dengan Harga Saham Sebagai Variabel Moderating Pada Perusahaan Manufaktur Yang Terdaftar Di Bursa Efek Indonesia. Journal of Information Technology and Accounting, I(1), 1-16.

Silitonga, H. P., Siregar, R. T., \& Susanti, E. (2019). DAMPAK QUICK RATIO DAN LONG TERM DEBT to EQUITY RATIO TERHADAP NILAI PERUSAHAAN. 4, 913. http://114.7.97.221/index.php/JMA/article/view/1017

Utomo, W., Andini, R., \& Raharjo, K. (2016). PENGARUH LEVERAGE (DER), PRICE BOOK VALUE (PBV), UKURAN PERUSAHAAN (SIZE), RETURN ON EQUITY (ROE), DEVIDEN PAYOUT RATIO (DPR) DAN LIKUIDITAS (CR) TERHADAP PRICE EARNING RATIO (PER) PADA PERUSAHAAN MANUFAKTUR YANG LISTING di BEI TAHUN 2009 - 2014. Journal of Accounting, 2(2).

Welly, Y. et al. (2019). FINANCIAL : Jurnal Akuntansi LEVERAGE DAN PROFITABILITAS TERHADAP NILAI DAN MINUMAN LEVERAGE AND PROFITABILITY OF CORPORATE VALUES WITH COMPANY Article History : yang menjadikan industri makanan dan ini menggunakan Price to Book Value ( PBV ). Alasan memi. Accounting Analysis Journal, 5, 1-10.

Zaki, M., Islahuddin, \& Shabri, M. (2017). Pengaruh Profitabilitas, Leverage Keuangan dan Ukuran Perusahaan Terhadap Harga Saham (Studi Pada Perusahaan Manufaktur Yang Terdaftar di Bursa Efek Indonesia Periode 2005-2014). Jurnal Megister Akuntansi, 6(2), 58-66. http://jurnal.unsyiah.ac.id/JAA/article/view/8969 